\title{
Taking the Bait from the Prescription Opioid Industry: a Mea Culpa
}

\author{
Diana J. Burgess, $P h D^{1,2}{ }^{\oplus}$, Erin E. Krebs, MD, $M P H^{1,2}$, and Craig S. Roth, $M D^{2}$ \\ ${ }^{1}$ Center for Care Delivery and Outcomes Research, Minneapolis Veterans Affairs Health Care System, One Veterans Drive (152), Minneapolis, MN, \\ USA; ${ }^{2}$ Department of Medicine, University of Minnesota, Minneapolis, MN, USA.
}

J Gen Intern Med 37(8):2072-3

DOI: $10.1007 / \mathrm{s} 11606-021-07381-5$

(C) This is a U.S. government work and not under copyright protection in the

U.S.; foreign copyright protection may apply 2022

$\mathrm{T}$ his is the story of a 2003 workshop designed to increase medical residents' willingness to prescribe opioids for chronic pain. $(1,2)$ CR developed and led the workshop, DB collaborated with $\mathrm{CR}$ on the resulting publications, and EK was a resident who participated in the workshop. It is also the story of the aftermath - reckoning with our roles, as physicians and pain researchers, and how we unwittingly "took the bait" set out by a massive prescription opioid industry marketing campaign, which targeted physicians, professional societies, academic institutions, patient advocacy organizations, legislators, public health agencies, and consumers.(3)

$C R$ : In 2003, I was practicing internal medicine and supervising residents at a Veterans Affairs (VA) hospital. Pain experts had convinced me I was undertreating pain and exaggerating the risks of opioids. Newer opioid formulations, especially long-acting ones, supposedly carried reduced risk for misuse. I cautiously began offering them in low doses to a few patients with chronic back pain. Many reported improved mobility, sleep, and functional capacity with few obvious adverse effects.

I developed what I believed was an evidence-based half-day workshop on managing chronic pain, utilizing consensus guidelines from the American Academy of Pain Medicine and the American Pain Society. During the workshop, I brought in two patients I considered "opioid success stories" and interviewed them. Resident attitudes toward prescribing opioids for chronic pain were changed by the workshop.(1) They indicated increased willingness to prescribe opioids and less concern about addiction or side effects.

$E K$ : As a resident participant with a pre-existing interest in pain management, I found the workshop compelling. The patients seemed similar to my own patients who were struggling with severe chronic pain. Afterwards, I felt motivated to

Received September 28, 2021

Accepted December 21, 2021

Published online January 19, 2022 prescribe opioids. I started with an older veteran who had severe osteoarthritis and was ineligible for joint replacement surgery. I prescribed hydrocodone and, when that was insufficient, added morphine SR. The initial pain relief was clear, although less than we had expected. I increased the dosage several times before completing my residency and leaving the clinic.

$D B$ : As an early career investigator, I welcomed the opportunity to collaborate on publications resulting from the workshop. I was studying racial disparities in opioid prescribing and was also concerned over the broader stigmatization of patients with chronic pain. Reducing physician negative attitudes toward opioids seemed to be part of de-stigmatizing patients with pain. The workshop seemed to be a step in the right direction.

$C R$ : As my experience using opioids for chronic pain grew, so did the number of negative consequences. Among them, hostile demands for escalating doses, patients experiencing withdrawal symptoms, negative behavioral and mood changes, pain contract violations, breaches of trust, and strained patient relationships.

$E K$ : After finishing residency, I considered myself a cautious opioid prescriber, following guideline recommendations to assess risk, monitor adherence, and intensify opioid therapy as needed to achieve pain relief. Over the years, this approach produced incidents of opioid-related injuries and oversedation in my primary care practice. One patient experienced serious harm, an opioid addiction that caused her to lose her job and her home. A more typical experience was that of a widower with chronic low back pain who plateaued on longacting opioids for a couple of years - "stable" with significant pain and no major adverse effects-before experiencing a long, slow functional decline. Although we had a trusting relationship, changing directions proved difficult. He was terrified of tapering. I felt uncomfortable continuing a failed treatment plan, guilty about causing harm, and unsure how to unravel the situation I had created.

$D B$ : I should have heeded the warning in 2007 when my wise colleague, Dr. Frank Lederle,(4) provided feedback on my VA grant proposal to assess racial disparities in pain assessment and opioid prescribing. "You're rearranging deck chairs on the Titanic," he told me, pointing out the lack of evidence supporting the use of long-term opioids for chronic pain. I submitted the grant and got it funded, with nary a 
reviewer questioning the premise that racial disparities in opioid prescribing was a key contributor to racial disparities in pain. At some point though, the evidence of a growing opioid overdose epidemic made it all too clear that I and other researchers should not be focusing our efforts on increasing rates of opioid prescribing to Black, relative to White, patients with chronic pain.

Fast forward to 2021. Thirty years of widespread opioid prescribing has fueled an epidemic of harm. We know now that physicians were a central part of the opioid industry's marketing strategy(3) and hindsight has given us insight into how we failed.

$C R$ : I now see that concepts I included in my workshop, such as "pseudo-addiction," were part of a marketing scheme to sell OxyContin and other opioids.(3) The now-defunct American Pain Society, whose guidelines formed the basis for my workshop, had received most of its support from Purdue Pharma at one point.(3) It was painful to feel duped and manipulated by the drug companies that I know caused harm to patients. I regret not being able to discern appropriate information for providing the best patient care and teaching. I also felt remorse, guilt, embarrassment, and shame. Writing this piece provided the first opportunity to give voice to these feelings and to contemplate ways of dealing with them.

$E K$ : I know that many of my physician colleagues are haunted by negative outcomes of their well-intentioned opioid prescribing. I wonder whether unresolved feelings of shame and grief contribute to some of our profession's maladaptive responses to the opioid crisis - avoiding patients with opioid problems, "over-correcting" in prescribing, blaming patients for harm they experience, and failing to address our contributions to the root causes of the crisis.

$D B$ : I am dismayed about how much effort intended to reduce racial disparities in pain was wasted on opioid prescribing. And I wonder - did we give cover to the prescription opioid manufacturers by framing increased opioid prescribing as a social justice issue?

Lessons for the Profession. We view our experiences through the lens of moral injury, defined as "perpetrating, failing to prevent, or bearing witness to acts that transgress deeply held moral beliefs and expectations."(5) Awareness of the past and admission of our contribution to this moral injury is the first step in healing. We have shared our regrets to claim our respective roles in the US opioid crisis, and to move forward without forgetting our past. And, because moral injury "locates the source of distress in a broken system, not a broken individual,"(6) the next steps involve addressing systemic factors at the root of this crisis. Clinicians and researchers can reduce the likelihood of future crises by advocating within our professional societies, medical centers, and educational institutions to reduce industry influence on health care delivery and health education. $(3,7)$

Corresponding Author: Diana J. Burgess, PhD; Center for Care Delivery and Outcomes Research, Minneapolis Veterans Affairs Health Care System, One Veterans Drive (152), Minneapolis, MN 55417, USA (e-mail: Diana.Burgess@va.gov).

\section{Declarations:}

Conflict of Interest: The authors declare that they do not have a conflict of interest.

Disclaimer: The views expressed in this article are those of the authors and do not represent the views of the VA or the US government.

Statement of support: This material is the result of work supported with resources and the use of facilities at the Minneapolis Veterans Affairs Health Care System.

\section{REFERENCES}

1. Roth CS, Burgess DJ. Changing residents' beliefs and concerns about treating chronic noncancer pain with opioids: evaluation of a pilot workshop. Pain Med. 2008;9(7):890-902.

2. Roth CS, Burgess DJ, Mahowald ML. Medical residents' beliefs and concerns about using opioids to treat chronic cancer and noncancer pain: a pilot study. J Rehabil Res Dev. 2007;44(2):263-270.

3. Marks JH. Lessons from corporate influence in the opioid epidemic: toward a norm of separation. Journal of Bioethical Inquiry. 2020;17(2):173-189.

4. Lederle FA. Terminal. Ann Intern Med. 2017;167(11):826-827.

5. Litz BT, Stein N, Delaney E, et al. Moral injury and moral repair in war veterans: a preliminary model and intervention strategy. Clin Psychol Rev. 2009;29(8):695-706.

6. Dean W, Talbot S, Dean A. Reframing Clinician Distress: Moral Injury Not Burnout. Fed Pract. 2019;36(9):400-402.

7. Uppal N, Anderson TS. Learning from the Opioid Epidemic: Preventing the Next Healthcare Marketing Crisis. J Gen Intern Med. 2021;36(1 1):3553-3556.

Publisher's Note Springer Nature remains neutral with regard to jurisdictional claims in published maps and institutional affiliations. 